\title{
Contribuições da Clínica da Atividade para o campo da segurança no trabalho
}

\author{
Clinic of Activity contributions to safety at work
}

${ }^{1}$ Universidade Federal de Minas

Gerais, Brasil.

\section{Resumo}

A partir da análise de um estudo realizado no setor petroleiro, em 1996, o artigo expõe os fundamentos da Clínica da Atividade (Clinique de l'Activité) - método de análise e compreensão do trabalho desenvolvido por Yves Clot, na França -, trazendo uma reflexão sobre suas possíveis contribuições para o campo da segurança no trabalho. A autora conclui que os conceitos de gênero de atividade e estilo (genre et style professionel), propostos por Yves Clot, são essenciais para a compreensão dos acidentes e suas causas.

Palavras-chaves: clínica da atividade, segurança no trabalho, acidentes industriais.

\begin{abstract}
Based on the analysis of a study held at the oil sector in 1996, the article presents the principles of the Clinic of Activity (Clinique de l'Activité) - a method for analyzing and understanding work developed by Yves Clot in France -, reflecting on its possible contribution to the field of safety at work. The author concludes that the concepts of professional framework and style (genre et style professionels) proposed by Yves Clot are essential for the comprehension of work related accidents and its causes.
\end{abstract}

Keywords: clinic of activity, safety at work, industrial accidents. 


\section{Introdução}

Inicialmente, cabe esclarecer que Clínica da Atividade é a denominação escolhida por Yves Clot para o método desenvolvido por ele e sua equipe no Conservatoire National des Arts et Métiers (CNAM), em Paris, onde é professor e responsável pelo Laboratório de Psicologia do Trabalho². Por ser um teórico ainda pouco conhecido no Brasil, tentaremos expor brevemente sua trajetória e os conceitos centrais que compõem seu campo de atuação.

${ }^{2}$ Sobre as questões teórico-metodológicas em torno da Clínica da Atividade, recomendamos a leitura de CLOT, Y. A função psicológica do trabalho. Petrópolis: Vozes, 2006.

${ }^{3}$ Para o leitor interessado em conhecer melhor sobre a trajetória de Yves Clot e suas fontes de inspiração, recomendamos a leitura de Le travail sans I' homme - pour une psychologie des mileux de travail et de vie. Paris: La Découverte, 1995 , e o posfácio "Un autre regard sur les usines". In: ODDONE, I.; RE, A.; BRIANTE, G. Rédécouvrir I'expérience ouvrière. Paris, Editions Sociales, 1981.

${ }^{4}$ Cf. A função psicológica do trabalho (op. cit.), na qual Clot constata, inclusive, um aumento da fadiga do trabalhador em função da intensidade do esforço que este tem de fazer para conter seus atos, isto é, para deixar de realizar suas atividades da forma que julga mais adequada. Ou seja, segundo ele, a fadiga não decorre tanto do que se faz, mas do esforço para não se fazer o que deveria ser feito, para recalcar a atividade.

${ }^{5}$ Todo esse item é baseado na obra de Y. Clot, A função psicológica do trabalho, já citada no início deste artigo. Assim, serão citadas apenas as páginas dessa obra da qual foram extraídas as citações.
Clot teve uma formação inicial em Filosofia, formando-se em Psicologia após seu doutoramento. Uma de suas maiores fontes de inspiração foi o trabalho de I. Oddonne, na Itália, na década de 1970, mas a base de suas reflexões tem sido as contribuições da chamada Psicologia Sócio-Histórica de Vygotski, Leontiev e Luria, além daquelas advindas dos estudos do lingüista russo M. Bakhtin em torno da análise do discurso. Entre seus antecessores, na França, apóia-se, sobretudo, em $\mathrm{H}$. Wallon, I. Meyerson e L. Le Guillant. ${ }^{3}$

Ele faz uma rica apropriação das obras desses teóricos, propondo uma abordagem original e, ao mesmo tempo, eficaz da atividade. Dessa abordagem, extraiu elementos de importância fundamental para compreendermos o lugar da subjetividade na análise do trabalho, propondo alguns conceitos importantes, dos quais três serão tratados aqui: o real da atividade, o gênero de atividade e o estilo da ação. O primeiro se refere à atividade do indivíduo sobre si mesmo, uma vez que, para nosso autor, a atividade do trabalhador não é jamais uma mera reação. Ela é uma espécie de filtro subjetivo que proporciona um sentido para a vida do sujeito bem diverso daquele que lhe depositam as atividades de concepção. Assim, às atividades prescrita e real, já previstas na Análise Ergonômica do Trabalho, ele acrescenta o real da atividade, que consiste naquilo que pode ser feito, mas não se faz: as atividades suspensas, contrariadas, sem possibilidades de realização. Ele distingue, dessa forma, a atividade realizada do real da atividade: a primeira é o que se faz e o segundo consiste no que não se pode fazer, no que se gostaria de fazer, no que poderia ter sido feito e mesmo no que se faz para não fazer aquilo que deve ser feito. ${ }^{4}$

Mas é sobre as noções de gênero e de estilo que pretendemos nos deter um pouco mais neste artigo, uma vez que repre- sentam, no nosso entender, as contribuições mais relevantes de Clot para o campo da segurança no trabalho.

\section{Gênero e estilo de atividade ${ }^{5}$}

Para Clot, gênero de atividade é um sistema de instrumentos, coletivamente construído e que se encontra no interior da atividade individual. É uma gama de atividades encorajadas, proibidas ou interditas. Um repertório disponível que pré-organiza a atividade. Ou seja, trata-se de técnicas, formas de fazer estabelecidas, uma reorganização do métier pelo coletivo e, dessa forma, pode ser compreendido como a parte subentendida da atividade, um estoque de possibilidades conhecido somente por aqueles que participam da mesma situação. Trata-se, portanto, de um instrumento coletivo da atividade individual.

Ele ressalta a necessidade constante de se recriar nos contextos de trabalho, dizendo que essa recriação é sempre única e que o gênero auxilia nesse processo. Mas aos que identificam gênero e cultura, esclarece que não está se referindo à cultura como idéia, pois esta seria uma visão instrumental do gênero. Trata-se, segundo ele, da cultura como prática, isto é, de um instrumento genérico da ação individual.

O gênero seria, portanto, uma espécie de senha para se saber o que é possível ou não esperar de uma situação. Aquilo que é permitido ou que é proibido em um métier. Trata-se de uma memória que não se refere apenas ao passado, mas que serve para prever o futuro, para antecipar, permitindo evitar possíveis erros no exercício da atividade, ou seja, é um:

(...) sistema aberto de regras impessoais, não escritas, que definem num meio dado, o uso dos objetos e o intercâmbio entre as pessoas; uma forma de rascunho social que esboça as relações dos homens entre si para agir sobre o mundo. (p. 50)

Em suma, pode-se definir gênero:

(...) como um sistema flexível de variantes normativas e de descrições que comportam vários cenários e um jogo de indeterminação que nos diz de que modo agem aqueles com quem trabalhamos, como agir ou deixar de agir em situações precisas; como bem realizar as transações entre colegas de trabalho requeridas pela vida em comum, organizada em torno de objetivos da ação. (p. 50) 
É o gênero, enfim, que:

(...) organiza a reciprocidade dos lugares e funções ao definir as atividades independentemente das propriedades subjetivas dos indivíduos que as realizam num momento específico. (p. 50)

Portanto, ele:

(...) não regula diretamente as relações entre as pessoas, mas antes as relações entre profissionais, ao fixar o 'espírito' dos lugares como instrumento de ação: diz, sem o dizer, o que deve fazer em tal ou qual situação o suposto desconhecido que jamais iríamos conhecer. (p. 50)

Mas, adverte Clot, não é o gênero que explica a atividade e sim esta que explica o gênero. Além disso, ele não pode ser "ensinado", pois é na atividade, ao lidar com os obstáculos, que o gênero é transmitido. Sua transmissão, portanto, é sempre indireta e ela se dá pelo exercício das atividades e pelo enfrentamento das dificuldades. Isso significa que é, muitas vezes, no fracasso que se mostra como fazer e o que as pessoas aprendem.

Nesse sentido, o gênero é fundamental e estruturalmente inacabado. Por isso, nosso autor alerta também para o perigo de que seja percebido como um molde, dizendo que, assim, ele pode necrosar. ${ }^{6} \mathrm{O}$ fechamento do gênero, portanto, é percebido por ele como algo perigoso, pois impede que seja utilizado não apenas pelos novatos que chegam ao local de trabalho, mas também pelos antigos, pois, para continuar a ser um instrumento, deve variar, permanecer vivo. Além disso, ao debater o gênero, os indivíduos o recriam e, se ele é um sistema de variantes, quanto mais choques ocorrerem entre as variantes, mais flexibilidade ele terá e menos ingênuo será o sujeito.

Ainda de acordo com Clot:

O gênero social, ao definir as fronteiras móveis do aceitável e do inaceitável no trabalho, ao organizar o encontro do sujeito com seus limites, requer o estilo pessoal. (p. 49)

Este, seria, então:

(...) a transformação dos gêneros, por um sujeito, em recursos para agir em suas atividades reais. Em outros termos, é o movimento mediante o qual esse sujeito se liberta do curso das atividades esperadas, não as negando. (p. 50)

Mas desenvolvendo-as.

Assim, o estilo emerge quando o trabalhador pode falar do métier, fazê-lo viver de forma plurivocal. É quando ele mobiliza a variabilidade e faz circular as variantes. Portanto:

(...) situa-se sempre no âmbito do gênero, ou, para ser mais precisos, no ponto de colisão entre as variantes do gênero, às quais recorre, alternativamente, de variadas maneiras, a depender do momento. (p. 50)

Dessa forma, o estilo se concretiza quando se cria a possibilidade de colocar em xeque o espírito categórico, sempre espreitado pela seriedade, pois, segundo Clot, esta passa a ser perigosa quando encarcera o gênero numa verdade, ou seja, quando impede o desenvolvimento do métier. Em outras palavras, um dos perigos que se apresentam é quanto ao excessivo estreitamento do gênero em relação à riqueza da atividade, pois quando ele se enrijece, a atividade necrosa. É por isso que se deve sempre evitar que ele se torne um clichê e que não possa transitar para um outro gênero, pois é nesse trânsito que os diferentes gêneros se contaminam e ocorre a estilização. E o que é mais importante para o tema central deste artigo: quando há degenerescência do gênero, há degenerescência da atividade, o que pode favorecer o desenvolvimento de patologias e também a ocorrência de acidentes no trabalho.

\section{Gênero de atividade e segurança no tra- balho}

Após o que foi dito a respeito de gênero e estilo, não é difícil perceber a relação entre essas noções propostas por Clot e a segurança nos contextos de trabalho. Ou seja, fica claro que se o gênero degenera, o desenvolvimento da atividade fica bloqueado, configurando uma situação de risco, pois a atividade passa a ser, sobretudo, uma fonte de sofrimento. Além disso, com a degenerescência do gênero, deixa de existir um coletivo para amparar o sujeito e relançar esse desenvolvimento. O sujeito tende, então, a ficar isolado, impossibilitado de mobilizar o recurso genérico e sem o suporte do coletivo.

O coletivo serve para interpor as formas de fazer estabilizadas entre o sujeito e ele mesmo. Ou seja, ele não é meramente uma soma ou uma "coleção" de indivíduos. É, acima de tudo, a fonte de uma história comum partilhada, momentaneamente estabilizada e que protege o indivíduo de si mesmo. Assim, cada trabalhador apela ao coletivo para tomar decisões. ${ }^{7}$

No entanto, nem toda equipe funciona como um coletivo e, sobretudo, nos dias
${ }^{6}$ Ele ilustra como isso se dá nos contextos de trabalho, citando uma situação bastante comum nas empresas que consiste em se dizer: "aqui se faz assim e não se discute", ao invés de se dizer: "aqui se faz assim, mas podemos discutir para ver se estamos no melhor caminho".

${ }^{7}$ Segundo Clot, quando o trabalhador diz: "a gente faz assim", o que está em jogo não é apenas a tarefa e sim toda a história da fábrica e, de certa forma, do métier. 
${ }^{8}$ Curso sobre Clínica da Atividade, ministrado por Yves Clot, na Unicamp, em maio de 2006.

${ }^{9}$ Idem.

${ }^{10}$ Idem.

${ }^{11}$ Em alguns casos, a empresa chega a demitir seus empregados, recontratando-os, em seguida, nesses novos termos. Ou seja, aquele empregado que, ontem, fazia parte do núcleo de contratados estáveis, amanhã poderá fazer parte do grupo dos terceirizados, submetido a contratos precários e salários bem mais baixos, embora executando basicamente as mesmas tarefas. Sobre esses aspectos perversos da terceirização no Brasil, veja Sampaio (2000) e Hazan (2001) atuais, o risco de degradação dos gêneros é bem maior, pois as empresas começam a comprometer sua história através das demissões em massa, dos Planos de Demissão Voluntária (PDVs) ou das formas contemporâneas de gerenciamento, muitas vezes acompanhadas do enxugamento dos quadros (Programas de Reengenharia) ou da intensificação dos processos de terceirização e subcontratação (Programas de Qualidade Total). Em todas essas situações, os trabalhadores se vêem vítimas daquilo que Clot chama de "amputação de sua história coletiva” (CLOT, 2006, p. 50).

Além disso, nosso autor constata que a atividade contrariada está no âmago da organização do trabalho contemporâneo, já que a responsabilidade é convocada e, ao mesmo tempo, posta de lado. São grandes os conflitos em torno do que é qualidade, por exemplo, ao se impor autoritariamente os programas e desconsiderar a perspectiva do trabalhador sobre o tema. E, o mais importante, em decorrência dessas novas estratégias gerenciais, os coletivos se desfazem e não têm sido recompostos, o que representa um risco considerável, pois, como já foi dito, eles têm, dentre outras funções, aquela de auxiliar os indivíduos na sua tomada de decisões. ${ }^{8}$

Mas devemos ressaltar também que, se o coletivo permite que o indivíduo se desenvolva, ele lhe impõe, ao mesmo tempo, certos limites, pois, como diz Clot, o trabalho comporta imensas possibilidades de engano e trabalhar é sempre correr o risco de errar. ${ }^{9}$ Nesse sentido, o coletivo atua também como protetor e é por isso que, se ele degenera, os "erros" tornam-se mais freqüentes. As portas tornam-se abertas para os acidentes, conforme atesta o autor ao falar do aumento recente de acidentes entre trabalhadores da construção civil na França, ocorrendo, paralelamente, ao incremento da terceirização no setor. ${ }^{10}$

É claro que, ao falar dessa possibilidade de erro, Clot não está se situando na mesma perspectiva dos autores que aderem às teses simplistas baseadas no "fator humano" e na sua antinomia em relação ao "fator técnico", cujo pressuposto maior é o da execução isolada da tarefa, além da crença na confiabilidade do último e na não confiabilidade consubstancial do primeiro (cf. MANDEL, 1999). Basta ler a análise de um acidente que ele realiza no primeiro capítulo do seu livro (CLOT, 2006) para constatar que sua perspectiva não pode ser absolutamente associada a esse tipo de reducionis- mo, que, infelizmente, ainda está presente nas análises sobre o assunto.

No Brasil, tudo indica que o problema da terceirização é mais grave, dadas as características ainda mais perversas assumidas pelos processos de terceirização. É sabido que, entre nós, esse recurso tem sido adotado pelas empresas como um artifício para redução de custos com a mãode-obra. Dessa forma, elas se concentram apenas nas suas atividades-fim, transferindo para as subcontratadas a execução das outras atividades (consideradas menos importantes), além da responsabilidade com a saúde e a segurança de um número crescente de empregados. Estes, por sua vez, são obrigados a aceitar salários reduzidos, contratos temporários, condições de risco, jornadas dilatadas e perda de benefícios importantes. ${ }^{11}$

Assim, diversas pesquisas apontam para uma estreita relação entre terceirização e aumento de acidentes de trabalho, trazendo evidências contundentes de que os trabalhadores terceirizados se acidentam mais e com maior gravidade do que aqueles que possuem formas estáveis de contratação (SAMPAIO, 2000; FERREIRA \& IGUTI, 1996). No entanto, ao tentar explicar esse dado, os pesquisadores, em geral, não conseguem ir além da constatação de que as empresas não oferecem aos terceirizados as mesmas condições oferecidas ao pessoal diretamente contratado por elas. Suas análises não esclarecem o verdadeiro motivo dessa estatística que se repete com regularidade. É exatamente nesse aspecto que a contribuição de Y. Clot nos parece relevante. Ele consegue tocar, no nosso entender, em um ponto crucial: a degradação dos gêneros de atividade, provocada por essas novas formas de organização da produção, pode ser a chave para a compreensão do problema.

\section{Análise de uma situação à luz das contri-} buições da Clínica da Atividade

A título de ilustração, gostaríamos de trazer aqui um estudo que nos parece particularmente revelador dessa relação estabelecida por Y. Clot entre coletivo, gênero de atividade e acidentes no trabalho. Ele foi realizado na Petrobrás (nos terminais de São Sebastião e de Alemoa/Santos e na Refinaria de Cubatão), entre abril de 1993 e maio de 1994, sob a coordenação de Leda Leal Ferreira (FERREIRA \& IGUTI, 1996).

Nesse estudo, os pesquisadores destacaram dois aspectos que diferenciavam a 
política de pessoal e a gestão da mão-deobra adotadas pela empresa na época e no passado: a terceirização dos serviços e a diminuição do efetivo operacional, sendo que esses dois fenômenos aconteciam simultaneamente. Ou seja, ao mesmo tempo em que a empresa diminuía seus efetivos, aumentava a contratação das empreiteiras. De modo que, na Refinaria de Cubatão, havia, naquela ocasião, quase dois empregados de empreiteiras para cada funcionário da Petrobrás, sendo que nos terminais essa proporção era ainda maior.

Embora a presença das empreiteiras fosse um fenômeno antigo na Petrobrás, o que se constatava naquele momento era sua intensificação, além de uma mudança no perfil dos trabalhadores terceirizados. Ou seja, eles apareceram, segundo um dos entrevistados:

primeiro, dentro do serviço de pátio; depois, dentro do serviço de restaurante.... depois, foram ocupando espaços dentro da manutenção propriamente dita e ocupando de tal maneira que já tem até uma empreitópolis lá dentro, já tem uma cidade de empreiteiras, de escritórios de empreiteiras, de vestiários. (id., p. 122)

Assim, a maioria dos serviços de manutenção foi transferida para as empreiteiras onde trabalhavam cerca de três mil pessoas na Refinaria de Cubatão e mais de mil nos terminais de São Sebastião e de Alemoa.

O aumento das aposentadorias, somado à proibição da contratação de pessoal, explica, em grande medida, o problema. Ou seja, as empreiteiras apareceram como a única alternativa para assegurar a continuidade dos trabalhos. No entanto, os pesquisadores constatam que tudo isso se deu de forma precária, ressaltando algumas conseqüências nefastas dessa prática: o aumento das desigualdades, a maior exposição aos riscos e, em decorrência do caráter temporário dos contratos, o surgimento de certas barreiras, impedindo o acúmulo de conhecimentos e a consolidação de compromissos entre os membros das equipes. Alguns depoimentos são reveladores a esse respeito:

O serviço é temporário. Fazem e vão embora. Deu problema, quem vai responder? (...) (id., p. 123)

A Petrobrás tem preocupação de dar cursos para você ter cada vez mais segurança e ficar aperfeiçoado. Agora, eu pergunto: qual é a empreiteira que vai dar curso para o cara trabalhar lá? (id., p. 123-124)
Você fica treinando pessoas da empreiteira (...) O pessoal que você treinou, no próximo contrato, não está mais lá. (...) (id., p. $123-124)^{12}$

É interessante ver os depoimentos daqueles que conheceram o sistema anterior, isto é, quando a equipe de manutenção era especializada e pertencia à Petrobrás. Em um deles, o trabalhador fala das "paradas" da refinaria antes e depois da transferência para as empreiteiras:

(...) No primeiro momento, havia duas equipes de manutenção própria da refinaria e é lógico que esse pessoal tinha um carinho maior de lidar com as coisas, mesmo porque era a mão dele que estava sendo colocada. Quem arrumou essa bomba? Foi o Queixada, foi o seu Pedro, foi o Maurício Negão, foi o Mineiro. Era a mão dele que estava ali. Ele tinha um carinho e fazia questão de saber: 'olha, onde eu pus a mão ficou bom'. Não tem rateio, era um negócio pessoal mesmo, de amor-próprio... A empreiteira vem e ela não tem compromisso nenhum com aquilo. O compromisso dela é cumprir o contrato. O cara chega lá, pega uma junta velha mesmo, não a junta daquela espessura, coloca ali no lugar; então, é esse relaxamento que, muitas vezes, ocasionou acidentes sérios lá dentro. (id., p. 124-125)

Tudo indica que a falta de continuidade das equipes impossibilitava o acúmulo de conhecimento ou, na perspectiva de Clot, impedia o desenvolvimento e a consolidação do gênero de atividade. Isso aumentava as chances de ocorrência de acidentes, sobretudo se levarmos em conta que estamos lidando com um processo de trabalho complexo, envolvendo enormes riscos e que, por isso mesmo, exige muita experiência acumulada para se alcançar certo domínio:

Quando o quadro de manutenção é da refinaria, ele é especializado. Trabalham com aqueles equipamentos dez, quinze, vinte anos, conhecem a manha do equipamento. (id., p. 125)

Na empreiteira, o que acontece? Um dia, vem um e conserta. Não fica bom. Passa uns tempos, vem outro. Então, embora a gente oriente, eles não têm a mesma capacidade. Porque não pode ter a mesma capacidade aquele que trabalha com aquela máquina um ano e um que trabalha vinte anos. Essa é a diferença. (id., p. 125)

Além disso, como já foi dito, ao mesmo tempo em que era intensificado o processo de terceirização, ocorria a redução dos efetivos operacionais da empresa, afetando ne-
${ }^{12}$ Estes e todos os grifos subsequientes são meus. 
gativamente a rotina. Um operador de processo expôs assim sua visão do problema:

Minha maior apreensão dentro da refinaria é o seguinte: com a redução do quadro mínimo, cai a qualidade da rotina. A rotina é uma coisa importantíssima, porque durante as rotinas feitas todos os dias, você vai detectando problemas futuros $e$ agravamento de problemas. (id., p. 131)

Ou seja, como parte da "modernização" da empresa, ocorria, na época, uma redução importante dos efetivos, sendo que, na Refinaria de Cubatão, por exemplo, eles haviam passado de 2.270, em 1987, para 1.608, em junho de 1993. A razão disso, de acordo com os autores da pesquisa, é o fato de que a empresa não estava contratando funcionários para repor aqueles que se aposentavam, mas, ao contrário, incentivava a aposentadoria. Tudo indica que ela pretendia adotar um efetivo operacional tão reduzido quanto o de algumas refinarias de países mais desenvolvidos, mas sem apresentar as mesmas condições tecnológicas e organizacionais. Havia também uma "orientação de corte de gastos" (id., p. 132) a fim de se alcançar o padrão de eficiência vigente, como se pode perceber no seguinte depoimento:

Como a Petrobrás está com uma orientação de corte de gastos por causa da tal idéia de eficiência, ela corta tudo. Só que para cortar em matéria-prima, não dá e a matéria-prima é a grande parte do custo da empresa. Para cortar em contrato de empreiteira, é uma coisa que eles não mexem. Cortar em peças e em equipamentos, eles zeraram praticamente o almoxarifado... Agora, o que eles têm para cortar? É só mão-de-obra. (id., p. 132)

De acordo com os pesquisadores, essa diminuição dos efetivos operacionais era um dos maiores problemas relatados pelos trabalhadores, surgindo em praticamente todas as reuniões. Foi criada, inclusive, a terminologia "quadro mínimo" para indicar:

o menor número de elementos por grupo de turno efetivamente necessário para a execução de tarefas sistematizadas que leve certa unidade a uma condição segura em caso de emergência. (id., p 132)

A adoção desse sistema gerou, dentre outras coisas, uma sobrecarga de trabalho, uma vez que cada equipe de turno só poderia trabalhar se tivesse seu quadro mínimo completo. Isso significa que um trabalhador do turno anterior poderia ser obrigado a substituir o colega que faltou, devendo, portanto, “dobrar” o turno. É interessante observar que esse "quadro mínimo" diminuía progressivamente:

\begin{abstract}
Esse quadro mínimo foi diminuído drasticamente. Nós começamos com onze, quando saí de lá nós éramos oito. Depois disso, eles foram cortando, chegou a seis e eles estavam querendo colocar cinco ou quatro. Veja bem: eles começaram a comparar a UGAV com a unidade que tinha lá nos EUA. Só que lá o computador faz tudo, os nossos equipamentos aqui não são iguais àqueles (....) (id., p. 133)
\end{abstract}

Portanto, a qualidade dos equipamentos disponíveis não correspondia aos novos padrões adotados para calcular os efetivos, conforme fica claro no seguinte depoimento:

Lógico que não dá para manter o efetivo reduzido como fizeram... Essa questão da automação e tecnologia moderna que importaram, colocaram painéis computadorizados para olhar caldeira, mas a caldeira está velha, obsoleta... Então, tem um painel, computador e tal, bonitinho, mas a caldeira está caindo aos pedaços, meu Deus!... (id., p.133)

O problema da redução dos efetivos foi percebido pelos pesquisadores sob dois ângulos fundamentais para o tema tratado neste artigo: o do desgaste pessoal e o da segurança, que é garantida, sobretudo, pela rotina. O depoimento a seguir integra bem esses dois ângulos:

\begin{abstract}
É lógico que o que vai agravando o nervosismo, me deixando mais apreensivo, é o corte de pessoal de operação e manutenção. Mais da operação porque, na minha opinião, o que determina que a unidade tenha uma continuidade operacional é uma rotina perfeita. E uma rotina exige número suficiente de operadores, para que eles tenham disponibilidade de perder tempo com a rotina. (id., p. 134)
\end{abstract}

Vale a pena ver a maneira como alguns trabalhadores interpretam essa medida adotada pela empresa:

A tarefa do operador é mais de observação do que física, a não ser em determinados momentos. Eles consideram que você está a toa. Só que você não está a toa. Primeiro, você está pensando no que está acontecendo. Não dá pra chegar lá e simplesmente desligar como se nada estivesse acontecendo. Segundo, sua tarefa é de observação, se variar... variou, você tem que atuar. Mas eles - a chefia, o corpo gerencial da empresa - trabalham muito com essa idéia de que você está a toa. (id., p. 135)

Quando a empresa reduz o efetivo, no raciocínio dela passa o seguinte: 'bom, eu tenho a probabilidade de, vamos supor, 
um para cem de acontecer um acidente no momento em que o pessoal está ocupado com outra tarefa'. Então, para eles, vale mais a pena contar com essa probabilidade de um para cem, esperando que em cem vezes vai acontecer isso, do que se precaver, prevenir essa única vez. Só que para a gente que está lá.... Se a gente esperar essa única vez.... Essa é que é a grande verdade. (id., p. 135-136)

Independentementedos verdadeirosmotivos que levaram a empresa a adotar essa medida, o que realmente importa é a conclusão dos pesquisadores de que "o número de funcionários 'dobrando' turno” era muito grande, sendo esta "uma prova objetiva de que o número de efetivos" estava "mal dimensionado", repercutindo gravemente "na segurança e na saúde dos trabalhadores" (id., p.136). Isso fica claro nos seguintes depoimentos:

Quando dobra... não dá pra explicar. Chega um ponto em que o cara vira um zumbi. Começa a falar nada com nada. Fica doido. E pior: ele traz aquele problema para dentro de casa também. Ele briga com a mulher, briga com os colegas, é uma barra! (id., p. 136)

São Sebastião é abençoado. Porque pelo número de funcionários que já se aposentou e não colocaram outros para trabalhar... esse terminal hoje em dia é uma bomba. (...) (id., p. 136-137)

Nas conclusões do estudo, seus autores reforçaram alguns pontos já tratados an-

\section{Considerações finais}

O que torna o estudo relatado acima particularmente interessante é o fato de seus resultados representarem uma espécie de antevisão do que viria em seguida. Ou seja, ele se tornou um marco entre as investigações realizadas sobre a Petrobrás, ao descrever um momento de transição entre uma empresa que conseguia controlar relativamente bem seus processos de trabalho, apresentando um índice reduzido de acidentes graves, para uma empresa na qual esse controle seria, em um curto período de tempo, posto em questão. $\mathrm{Na}$ conclusão do estudo, os autores constataram que, em comparação com o que ocorria em outras partes do mundo, a Petrobrás era uma empresa na qual os grandes acidentes eram raros. Para melhor fundamentar essa informação, citaram um levantamento, realizado em 1989, sobre os cem maiores aci- teriormente, mas que vale a pena retomar sinteticamente:

- a atividade do petroleiro é bastante complexa e perigosa, exigindo dele um alto grau de competência e responsabilidade;

- a segurança da refinaria decorre, fundamentalmente, dessa competência e dessa responsabilidade, pois são elas que se contrapõem "ao perigo que está em toda parte” (id., p. 142);

- o trabalho do petroleiro é, basicamente, um trabalho de equipe;

- o coletivo de trabalho tem um papel fundamental, isto é, um coletivo bem constituído “(...) é a melhor garantia para o bom funcionamento e a segurança de complexos industriais" (id., p. 143).

Ou seja, o estudo deixou claro que a política adotada pela empresa, ao privilegiar a terceirização e a redução dos efetivos, estava colocando em perigo seu próprio funcionamento e potencializando os riscos, já que afetava diretamente todos os aspectos considerados pelos pesquisadores como sendo a chave para a realização do trabalho em condições de segurança. Em outras palavras, pela sua riqueza e pela pertinência dos seus achados, ele acabou representando um alerta para aquilo que estava por vir.

dentes com perdas materiais ocorridos nos trinta anos anteriores em refinarias, petroquímicas, usinas de processamento de gás e terminais, dizendo que apenas um aconteceu no Brasil. É claro que, entre 1989 e 1997, que é o intervalo entre a divulgação da estatística acima e a publicação dos resultados do estudo, ocorreram acidentes importantes na empresa, mas, ao que tudo indica, houve uma aumento progressivo, em quantidade e gravidade dos mesmos após esse período. Isso significa que, pouco tempo após a divulgação dos resultados desse estudo, a Petrobrás passou a viver um difícil período de sua história durante o qual diversos acidentes graves ocorreram, culminando no trágico afundamento da Plataforma P36, em 2001.

Não é nossa intenção fazer um levantamento minucioso de todos os acidentes 
${ }^{13}$ http://www.ambientebrasil.com. br/composer.php3?base = ./agua/ salgada/index.html\&conteudo=./ agua/salgada/vazamentos.htm.

${ }^{14} \mathrm{O}$ relatório da Agência Nacional de Petróleo (ANP) sobre esse acidente concluiu que ele foi causado por erros de projeto, manutenção e operação. Algum tempo após, a direção da empresa admitiu a necessidade de reduzir o número de empregados terceirizados, assumindo ser este um importante fator na origem do grande número de acidentes que estava ocorrendo.

${ }^{15}$ A Federação dos Petroleiros, por exemplo, denunciou, em reportagem da Revista Época de 17/10/2002, as péssimas condições de trabalho a que eram expostos os trabalhadores das empreiteiras, dizendo que, entre 1998 e 2002, morreram 124 petroleiros, sendo 94 terceirizados. Em um boletim, datado de 15/03/2006, ela abordou novamente o problema, qualificando-o, acertadamente, como "tragédia anunciada". Um parlamentar que tem se pronunciado a esse respeito é Fernando Gabeira, em entrevistas à imprensa e no seu site. ocorridos na Petrobrás desde 1997, ocasião em que a pesquisa acima foi divulgada. $\mathrm{Na}$ verdade, o que interessa aqui é registrar o aumento progressivo dos acidentes mais graves, sobretudo a partir de 18 de janeiro de 2000, quando ocorreu o grande vazamento na Baía da Guanabara. Logo em seguida, ocorreram, sucessivamente, seis vazamentos importantes: em Tramandaí (Porto Alegre), em 11 de março de 2000; no Terminal Almirante Barroso, em São Sebastião (Norte de São Paulo), em 16 de março de 2000; novamente na Baía da Guanabara, em 26 de junho de 2000; na Refinaria Getúlio Vargas, em Araucária, no Paraná, em 16 de julho de 2000; em Paracambi, na Baixada Fluminense, em 31 de julho de 2000; e no Rio Grande do Norte, em 11 de agosto de $2000 .^{13}$

Na realidade, desde 1997, já é possível registrar acidentes importantes, como o rompimento de um duto da Petrobrás que liga a Refinaria de Duque de Caxias (RJ) ao terminal DSTE-Ilha D’Água, provocando o vazamento de 2,8 milhões de óleo combustível em manguezais na Baía da Guanabara (RJ), em 10 de março de 1997; o vazamento de FLO (produto usado para a limpeza ou selagem de equipamentos) no rio Cubatão (SP), em 21 de julho de 1997; o vazamento de 2 mil litros de óleo combustível, atingindo cinco praias na Ilha do Governador (RJ), em 16 de agosto de 1997; o vazamento de 1,5 milhão de litros de óleo combustível no rio Alambari, em 13 de Outubro de 1998, provocado por uma rachadura de cerca de um metro no trecho que liga a refinaria de São José dos Campos ao Terminal de Guararema (ambos em São Paulo), sendo que o duto estava há cinco anos sem manutenção; vazamento de 3 mil litros de óleo no oleoduto da refinaria da Petrobrás que abastece a Manaus Energia (Reman), atingindo o Igarapé do Cururu (AM) e o Rio Negro, em 6 de agosto de 1999; vazamento de 3 metros cúbicos de nafta de xisto, produto que possui benzeno, na Repar (na grande Curitiba), em 24 de agosto de 1999; menos de um mês após, em 29 de agosto de 1999, ocorreu um novo vazamento de óleo combustível na Reman, contaminando o Rio Negro (AM) com pelo menos mil litros de óleo; e, finalmente, em novembro de 1999, em Carmópolis (SE), ocorreu um vazamento de óleo e água sanitária no Rio Siriri (SE), sendo que a pesca no local acabou após o acidente.

Tudo isso culminou, conforme já foi dito, no afundamento da Plataforma P36, a maior do mundo, em março de 2001. O mais grave acidente da história da empresa teve repercussão mundial e obrigou seus dirigentes a repensar suas políticas, inclusive aquela relativa à terceirização. ${ }^{14}$ Isso não impediu que, apenas um ano depois, em 2002, ocorresse um incidente grave, felizmente, sem vítimas: o adernamento da Plataforma P34, na Bacia de Campos (RJ). Novamente, as críticas recaíram sobre a política de contratação intensiva de mãode-obra terceirizada pela Petrobrás, que foi acusada de contratar serviços de empresas que não adotavam os mesmos critérios de segurança. Ou seja, o problema persistia, embora fosse constantemente denunciado pelos trabalhadores e seus representantes, pela mídia e por parlamentares. ${ }^{15}$

Acreditamos que as evidências expostas acima são suficientes para ilustrar o que pretendíamos, ou seja, que a dupla medida adotada pela Petrobrás (redução dos efetivos e contratação de um número maior de empreiteiras) pode ter sido o fator preponderante para explicar o aumento de acidentes graves ocorridos na empresa. Na realidade, isso já estava posto, pelo menos como possibilidade, na análise feita pela equipe de pesquisadores, em cujo relato nos inspiramos para levantar essa hipótese.

Evidentemente, não é possível ir além disso, ou seja, o máximo que podemos nos permitir é levantar uma hipótese sobre o papel dessas medidas na gênese dos acidentes ocorridos na Petrobrás, uma vez que não fizemos uma análise detalhada sobre os mesmos e nem tivemos acesso aos relatórios completos sobre suas causas. Além disso, não se pode negligenciar o fato de que os acidentes são fenômenos complexos para os quais muitos fatores concorrem, devendo, todos eles, ser considerados ao nos debruçarmos sobre sua gênese. No entanto, nada disso afeta o peso das evidências trazidas neste artigo, uma vez que a redução dos efetivos e a intensificação da terceirização têm sido os dois fatores mais apontados pelos analistas (mas também pelos trabalhadores e seus representantes) para explicar o aumento dos acidentes graves nessa empresa. Finalmente, a própria direção da Petrobrás parece ter reconhecido o problema ao tomar medidas que revelam claramente sua decisão de mudar essas políticas.

Ao considerarmos as teses defendidas por Y. Clot, fica fácil compreender o peso que possui qualquer medida suscetível de afetar o funcionamento de um coletivo de 
trabalhadores, sobretudo quando se está lidando com processos complexos e perigosos, como são os do setor petroquímico.

Vale a pena trazer aqui algumas considerações feitas pelo autor a respeito do gênero de atividade e do seu papel em situações incidentais. Ele inicia reafirmando que gênero é:

a parte subentendida de atividade, aquilo que os trabalhadores de um dado meio conhecem e vêem, esperam e reconhecem, apreciam e temem; aquilo que é comum a eles e que os reúne sob condições reais de vida; aquilo que sabem que devem fazer graças à comunidade de avaliações pressupostas, sem que seja necessário especificar novamente a tarefa a cada vez que ela se apresenta. (CLOT, 2006, p. 11)

Trata-se, portanto, de uma espécie de "senha" conhecida apenas "por aqueles que pertencem ao mesmo horizonte social e profissional” (id., p.11). Em seguida, estabelece uma relação entre essa noção e a segurança no trabalho, ao dizer que "essas avaliações comuns subentendidas assumem, nas situações incidentais, um significado particularmente importante", uma vez que:

\section{Referências}

CLOT, Y. A função psicológica do trabalho. Petrópolis: Vozes, 2006.

CLOT, Y.; FAÏTA, D. Genres et styles en analyse du travail: concepts et méthodes. Travailler: Revue Internationale de Psychopathologie et de Psychodynamique du Travail, Paris, n. 4, p. 7-42, 2000.

FERREIRA, L. L.; IGUTI, A. M. O trabalho dos petroleiros: perigoso, complexo, contínuo e coletivo. São Paulo: Scritta, 1996.

HAZAN, H. M. F. Terceirização: a subordinação das empresas terceiras às tomadoras de serviços. In: NETO, A. C.; AMORIM, C. (orgs.). Novos desafios para ser eficazes, elas são econômicas e, freqüentemente, não são nem mesmo enunciadas. Elas entram no sangue dos profissionais, pré-organizam suas operações e sua conduta (...) (id., p.11)

E é exatamente por isso que "não requerem necessariamente formulações verbais". Portanto, para Clot "o gênero como interposto social, é um corpo de avaliações compartilhadas que organizam a atividade pessoal de forma tácita”, sendo por isso qualificada por ele como "a 'alma social' da atividade" (id., p.11).

Ora, as evidências acima reportadas, sobretudo aquelas advindas dos testemunhos dos próprios trabalhadores, seriam reveladoras de que a atividade do petroleiro foi atingida na sua essência ou, para retomar a feliz expressão de Clot, na sua "alma social”? Se a resposta for positiva, então a hipótese de que esse problema estaria no cerne da compreensão dos graves acidentes enfrentados pela empresa no decorrer dos últimos anos não nos parece frágil. Ao contrário, ela deveria, no nosso entender, ser levada a sério e aprofundada pelos analistas e responsáveis diretos pela segurança dessa e de outras empresas, cujos processos são igualmente "complexos", "perigosos" e "coletivos".

em saúde e segurança no trabalho. Belo Horizonte: Instituto de Relações do Trabalho, Fundacentro e Segrac, 2001.

MENDEL, G. Prefácio. In: LLORY. M. Acidentes industriais: o custo do silêncio. Rio de Janeiro: MultiMais Editorial, 1999.

SAMPAIO, M. R. O processo de qualificação real e o perfil de acidentabilidade entre trabalhadores efetivos e terceirizados: o caso dos pedreiros refrataristas de uma indústria de aço. 2000. Dissertação (Mestrado em Engenharia de Produção) - Escola de Engenharia, Universidade Federal de Minas Gerais, 2000. 